to comment on science, but also represents a form of research and knowledge production in its own right, though one belonging to a radically different epistemological tradition. Science, engineering and technology shape the world in which we live, but Ede shows us the role played by art in the ever more complex interplay of forces between science, technology and society. It is the artist who asks about the social effects of scientific developments and challenges the changing scientific concepts of life itself - these questions become ever more urgent with every scientific advance. Moving beyond the postulated dichotomy of the objective sciences and the subjective arts, the impressive abundance of contemporary artworks cited by Ede shows us that art is no longer limited to the production of beautiful atefacts, but has established its role as a legitimate form of knowledge production in its own right.

The engagement of art with science ranges from artists' iconological handling of scientific imaging to research projects executed as artistic endeavours by artists working in the laboratory. An example of the former is the work of Neal White, one-time artist in residence at the human genome project at Hinxton near Cambridge, UK; an example of the latter is the work of the Portuguese artist Marta de Menezes, who uses the laboratory technique of microcautery to modify the patterning of butterfly wings. Such artistic interventions in genetics and biological forms have made possible new means of artistic expression and art forms.

Some of the insights that art provides into the latest hot topics in science, such as cloning or the production of artificial chimaeras, have been extensively addressed by Suzanne Anker and Dorothy Nelkin in their book The Molecular Gaze (Cold Spring Harbor Laboratory Press, 2004). The use of biological materials by artists ranges from tissue engineering to stem-cell technologies and even transgenic animals, a phenomenon that raises ethical questions with regard to both scientific and artistic endeavours.

New directions in research, such as those offered by neurobiology and studies of consciousness, provide greater insight into the working of the mind, and molecular biology continues to provide us with a better understanding of the structure of the living world. Their scientific explanations of the structures and processes of body and mind challenge our conception and understanding of what we call 'human nature'. But individuality and self must be more than mere bundles of impulses, sensations and chemical processes.

Through the use of video endoscopies in her 1994 work Corps étranger, artist Mona Hatoum blurs the boundaries between the inner and the outer, allowing the viewer to participate in her own stream-of-consciousness and somatic experiences. Collaborating with neuroscientists, artist Annie Cattrell uses functional magnetic resonance imaging (fMRI) data to create three-dimensional, amber-coloured works in resin that are then embedded in solid, clear, resin cubes or 'brain boxes' (see Nature 424, 18, 2002). Whether working with brain scans produced by advanced imaging processes or simply with traditional media, the focus of the artistic process is increasingly the diversity of human experience, something that often does not lend itself to portrayal using standard scientific procedures.

From the end of the nineteenth century onward, art has increasingly turned away from the classical quest for order, and has struggled on many levels with the disintegration of a uniform world view and a coherent conception of humanity. Scientific images today offer us amazing insights, but they must still be viewed as historical snapshots. Although modern science can provide us with ever more detailed pictures of the inner workings of our bodies and of the living world, the influence of such images on our understanding of the nature of humanity remains an issue for social discourse.

Ede not only offers an overview of contemporary art practices, but also examines their philosophical background. Additionally, the artworks discussed are accompanied by extensive examples of contemporary science and research, providing further insight into the newest scientific developments. The book is an excellent contribution to the literature in the field of art and science, and provides a perspective that reaches far beyond the usual approaches to the relationship between, and intersection of, art and science.

Ingeborg Reichle is an art historian and theorist at the Berlin-Brandenburg Academy of Sciences and Humanities, Jägerstrasse 22/23,

Berlin 10117, Germany.

\title{
Focusing on the stars
}

\section{Stargazer: The Life and Times of the \\ Telescope \\ Fred Watson \\ Da Capo Press: 2005.342 pp. $\$ 24.95$}

\section{Robert H. van Gent}

The telescope symbolizes the science of astronomy and had

a pivotal role in the development of early modern science. Several excellent historical studies have already been written about it, notably André Danjon and André Couder's Lunettes et Télescopes in 1935, Henry King's The History of the Telescope in 1955, and Rolf Riekher's Fernrohre und ihre Meister in 1990.

As we approach the fourth centennial of the invention of the telescope, the Australian astronomer Fred Watson presents a well-written, up-to-date history of the invention and development of the telescope and its impact on astronomy. As the astronomerin-charge at the Anglo-Australian Observatory at Coonabarabran in New South Wales, Watson is well equipped to write such a history. He tells the fascinating story of the invention of simple telescopes by Dutch spectacle-makers in the early years of the seventeenth century, and recounts their evolution into the modern telescopes of today.

The reliably documented history of the telescope begins in

September 1608, when the Middelburg spectacle-maker Hans Lippershey submitted a request for a patent on his invention. But Watson also dwells on the (unlikely) possibility that primitive telescopes had been known to the ancient Mesopotamians, and to Hellenistic and medieval scholars in Europe.

A stronger case can be made for the so-called Elizabethan telescope, an early reflecting telescope described in the works of the Englishmen Thomas Digges and William Bourne, but the evidence suggests that it existed only in the minds of those who wrote on it, rather than in reality. Although the inventors of the refracting telescope were Dutchmen, it fell to Galileo, Thomas Harriot and Simon Marius to use it to observe the Universe. Their observations soon provided proof for the Sun-centred copernican model of the heavens. Christiaan Huygens, Johannes Hevelius and William Herschel all made key discoveries using telescopes that they had designed and built themselves.

IMAGE UNAVAILABLE FOR COPYRIGHT REASONS After the early successes, Watson goes on to describe the subsequent improvements of the refracting and reflecting telescopes, with considerable attention to detail. In

Star performer: Galileo's telescope from the early seventeenth century. 
the final chapters, he discusses the great Earthand space-based telescopes of the twentieth century that revolutionized our understanding of the origin and fate of the cosmos, and he offers a peek into the near future at a new generation of super telescopes that will probe even further into space.

Throughout the text there are useful diagrams and illustrations that ably illustrate the various lens and mirror configurations that have been designed during the telescope's first 400 years. There are also detailed notes, a glossary of astronomical and optical terms, and a bibliography.

Inevitably, there are a few minor errors. For example, Ptolemy's Almagest, an astronomy manual, should be dated to the middle of the second century AD, not the first century AD.
Watson's book is a welcome addition to the literature on the history of the telescope, and can be recommended to any reader with an interest in the history of science and instrumental technology.

Robert H. van Gent is at the Institute for the History and Foundations of Science, Utrecht University, Utrecht NL-3508 TA, The Netherlands.

\section{Marine undercurrents}

\section{An installation by Ellen Gallagher builds on some little-known work by Sigmund Freud.}

\begin{abstract}
Colin Martin
The house in Hampstead, London, where Sigmund Freud lived during the last year of his life, after leaving Vienna in 1938, has been a museum since 1986. His youngest daughter Anna, who died in 1982, left the study and library exactly as Freud used them, crammed with his furniture, books and extensive collection of antiquities. The house has a palpable sense of intellectual continuity, which has inspired contemporary artists to engage with Freud's ideas and create work for display there. American artist Ellen Gallagher's current installation, Ichthyosaurus, cites early work by Freud that he rarely mentioned in his later years. Although best
\end{abstract} known as the founder of psychoanalysis, Freud also worked as a neurologist and anatomist between 1876 and 1896. He began his scientific career assisting the physiologist Ernst Wilhelm von Brücke in Vienna, studying the spinal nerve ganglia of a primitive fish, the lamprey (Petromyzon), to gain insight into the evolution of nervous systems.

Fifteen of Freud's drawings of Petromyzon from 1876 and 1877 (like the example shown on the right) are displayed for the first time, in conjunction with Gallagher's installation. Her interventions in his library and study are discreet, and their extent becomes apparent only after looking carefully into the cordoned-off rooms. Immediately obvious are two 16-mm films made in collaboration with Edgar Cleijne, Ichthyosaurus 2005, which are projected onto the walls. Although they initially appear to be family home movies, they are cinematic riffs on Gallagher's marine theme: one shows flailing

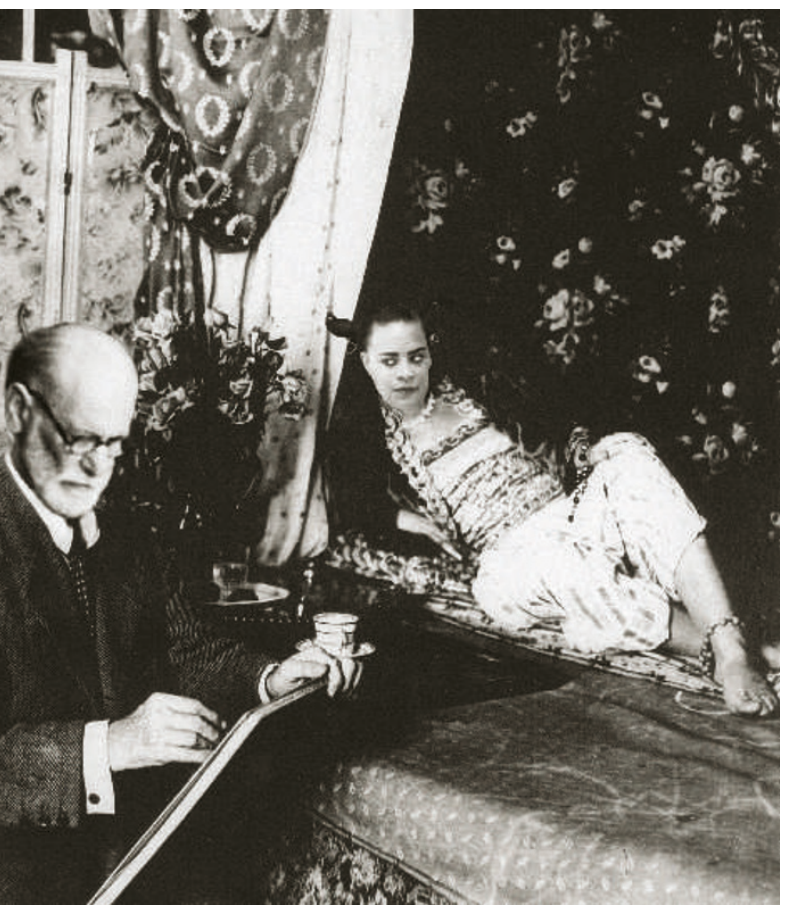

has hung three mixed-media works from her 'Watery Ecstatic' series, begun in 2001, on his walls. Fortunately, it is possible to view two further works located in the hall more closely and appreciate her skilful use of various techniques. These include intricately cut and coloured paper to form fish scales in Watery Ecstatic 2005 and cut layers of uncoloured paper to form fossil-like imprints of marine species in Watery Ecstatic (22 078 N, 159322 W) 2005.

Although her work is beautiful, it is unclear how Gallagher's appropriation of marine imagery provides more than a cursory nod towards Freud's early scientific work. His intention was simply to make

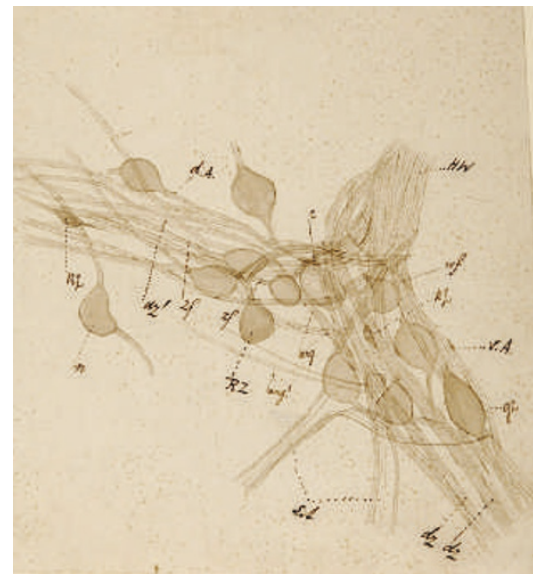

strands of seaweed, and the other spotlights various marine specimens that are difficult to discern from a distance.

Gallagher has also placed three glass specimen jars containing fanciful marine creatures among Freud's own objects, and drawings that presented cellular structure clearly, whereas she attempts to present multilayered personal and cultural meanings in her work.

Freud's influence appears more marked in Gallagher's two playful collages inspired by surrealism, the artistic movement that evolved from his psychoanalytical theories. In her photomontage Odalisque 2005 (shown here, above left), a seductively reclining Gallagher fails to divert Freud from his drawing board. In Abu Simbel 2005, she reworks a copy of the photogravure of an Egyptian temple that used to hang above Freud's couch in Vienna, adding a marinelike spacecraft complete with blue fur tentacles, which zaps rays at the colossal statues of Rameses II.

Ichthyosaurus can be seen at the Freud Museum (www.freud.org.uk) in London until 11 September.

Colin Martin is a London-based writer. 